\title{
The Accuracy Analysis of Measurement Tools for Traffic Accident Investigation
}

\author{
Darja Topolšek $^{1}$, Elvis A. Herbaj ${ }^{2}$, Marjan Sternad ${ }^{1}$ \\ ${ }^{1}$ University of Maribor, Faculty of Logistics Department, Celje, Slovenia \\ ${ }^{2}$ Police Directorate Celje, Celje, Slovenia \\ Email: darja.topolsek@fl.uni-mb.si, elvis.herbaj@policija.si, marjan.sternad@fl.uni-mb.si
}

Received September 19, 2013; revised October 16; 2013; accepted November 13, 2013

Copyright (C 2014 Darja Topolšek et al. This is an open access article distributed under the Creative Commons Attribution License, which permits unrestricted use, distribution, and reproduction in any medium, provided the original work is properly cited. In accordance of the Creative Commons Attribution License all Copyrights (C) 2014 are reserved for SCIRP and the owner of the intellectual property Darja Topolšek et al. All Copyright (C) 2014 are guarded by law and by SCIRP as a guardian.

\begin{abstract}
The objective of traffic accident reconstruction is to recreate the event, which is necessary for analyzing the collision dynamics that is used as evidence in court cases. Traffic accident reconstruction and a demonstration of the event require precise data pertaining to scene measurement. However, there are differences between the individual measuring tools and methods related to traffic accident investigation, just as there are differences between the extent of their use and measurement accuracy. The most commonly applied method is the measuring tape, followed by measurements with total stations and laser rangefinders, while photogrammetry is also becoming increasingly important. The advantages and disadvantages of individual tools and methods affect the required number of investigators, portability, measurement range, applicability depending on the amount of light and weather conditions, on the possibility of remote measurement, on data collection time, on the scope, on the option to later process, the collected data and above all on the accuracy of all gathered data. The latter is crucial for proving the guilt or innocence of traffic accident participants at court, as inaccurate data can lead to an unjust sentence. Measurement accuracy using the above mentioned tools and methods also varies depending on which ones are used, as well as on other factors.
\end{abstract}

\section{KEYWORDS}

Traffic Accident; Measurement Tools; Data Accuracy

\section{Introduction}

The number of road traffic accidents is constantly on the rise, which can be attributed to the increasing number of vehicles and drivers and to a higher standard of living. Such increase in the number of traffic accidents creates additional workload for law enforcement personnel, since they have to process more traffic accident scenes, which can cause time constraints for data collection at individual accident sites, resulting in less accurate data.

Collecting data at traffic accident scenes, especially data related to gathering evidence and performing measurements for processing the scene, can lead to certain factors, which affect other traffic participants. According to certain studies, closing down a main road can cause costs of up to $€ 140,000$ per hour of closure. In addition, closing down a road also affects other traffic participants, since drivers are usually frustrated when they have to wait for a traffic accident site to be cleared. Therefore, the shutdown period of the road due to a traffic accident must be kept as short as possible.

Data collection methods, measurement tools and the quality of collected data, depending on the measurement tool that is used, are crucial for making a quality drawing of the scene. However, collecting quality data from an accident scene requires a certain amount of time. Since investigators strive to shorten the time required for performing measurements at the accident site, this can unintentionally negatively affect the accuracy of the collected data, which can in turn significantly influence the verdict in case of a serious traffic accident. Reduced measurement accuracy can therefore lead to an unjust conviction or acquittal of a traffic accident participant. 
Data collection speed and accuracy depend on which methods and tools were used. Different countries use different methods and measurement tools for traffic accident investigation. These tools can range from classic methods like adhesive tape ruler to tachymeters, complex total stations, GPS, photogrammetry [1] and all the way to modern laser scanners.

The most common investigation activities used for documenting traffic accident scenes include: photography, collecting video data and scene measurements, followed by a detailed drawing of the scene [2].

The most commonly used method for collecting spatial data is the $2 \mathrm{D}$ method, where measurements are carried out along and offset from the road edge or centreline. Total stations and laser rangefinders are also commonly used tools; GPS has been successfully used as well, however, only in areas where there were no obstructions. Recent developments include close-range digital photogrammetric systems [3,4] which provide fast and accurate data acquisition but can be relatively expensive and complex to use for local police and traffic agencies.

Introducing the terrestrial laser scanning method enabled 3D documentation of the accident site in a much safer manner, since data were collected from a remote location, which enabled uninterrupted work of other units at the scene. This method of data acquisition is much more flexible, faster and can be used both in total darkness and direct sunlight.

In practice, police departments use different types of measuring equipment; how frequently each of them is used was researched by Walton et al. [2], whose study found that in Kentucky $60 \%$ of measurements were done with tape measures/measuring wheels, $24 \%$ with total stations, $13 \%$ with lasers and 3\% with other tools. The same study also examined which methods of reconstruction were used by responding state police agencies at the US national level, arriving at the following conclusion: tape measure-39\%, laser- $12.5 \%$, photogrammetry$12.5 \%$ and total stations-36\%.

The most commonly used data collection tool for accident scene investigation and for making a drawing of the accident is the tape measure or the measuring wheel, which represents the coordinate method of measuring the axes of the coordinate system, a triangular or polar coordinate system. This is the basic method that is still the most often used despite modern techniques and technologies that are now available. This method involves using a tape measure or measuring wheel to document the crash scene; however, electronic distance meters or laser instruments can also be used.

Accurate, quality and comprehensive traffic accident reports are crucial for entering data into data banks and for performing spatial analyses. Recently, Khan et al. [5] reviewed the traffic accident report forms that were used by the police departments in different districts and found that these forms can contain up to 99 different pieces of information pertaining to the accident scene. However, the accuracy and quality of these data did not reach a satisfactory level.

Considering the technological progress made until today, modern measurement tools should be used and not ignored. Modern systems guarantee timely, fast, accurate, integrated, accessible, standardized and uniform data. Also, the measurement process should disrupt the traffic as little as possible and provide end products that are easily transformed into 2D drawings [6].

However, with the enhanced scrutiny of any evidence in a court, and the need for the accident reconstruction data collection process to be as least disruptive to traffic as possible, the requirement has arisen for more comprehensive and accurate data to be recorded in the shortest time possible [7].

\section{Material and Methods}

The study is based on tests of research equipment and on a review of the relevant literature.

\section{Case Report}

The case report of this study contains a field simulation of a traffic accident, which allowed us to investigate the accident scene and carry out the required measurements. A statistic analysis of investigating the simulated traffic accident scene represents the second phase of studying a more serious traffic accident and also includes field measurements of where the participants, vehicles and traces were located. These measurements were carried out using three different methods: the coordinate method (measurements carried out by two police officers), with an electronic tachymeter or a robotic total station with an Imaging Station photo camera (measurements performed by two persons) and with the use of GPS-Hiper Pro receiver (measurements carried out by one person).

First, measurements using the coordinate method were carried out by two traffic investigators. They carried out on-site measurements using a measuring tape and made a croquis drawing. They used the classic rectangular measurement method, which is the standard method employed by the Slovene police for all measurements when a drawing has to be done on site. The method itself is reliable enough if the investigators are meticulous and perform the measurements according to instructions. Of course, measurement accuracy also depends on terrain configuration and road infrastructure. Particularly the latter is often not taken into account, which can lead to a gap between the "recorded" situation and the actual situation on site. At the police station, a qualified or skilled draughtsman redrew the croquis drawing as a hand- 
drawn precise drawing according to the technical drawing rules. The data collection time was not recorded separately, which is in this case justified due to the gradual acquisition of data with all the required measuring tools.

Then, measurements using the electronic tachymeter Topcon Imaging Station (IS) were carried out by two persons (in this case they did not use the Remote Control System 3 (RC-3), which enables remote IS control). First, they carried out laser measurements of the same objects that were measured with a measuring tape in the previous example. Data was collected in the form of dots and lines. This enables a complete visualisation and a 3D model of the scene. The data collected on site was then imported into the ACAD environment, where it was compared to the results of other measuring equipment that was used in the experiment.

Finally, measurements with the Topcon GPS+ Hiper Pro receiver were carried out by a single operator, who measured the same objects that were previously measured with IS and the measuring tape. The collected data was spatially located and includes point and line data. The measured data was subsequently imported into the ACAD environment and compared to the others.

All the measurements and data processing was done based on regulations for on-site data acquisition in accordance with the Act of Rules in Road Transport (OG RS nr. 109/2010), which specifies that police officers must arrive at a category II, III or IV traffic accident scene, ... and process the scene or arrive at a category I traffic accident scene and gather the facts and evidence. When using the measuring tape a croquis drawing was done at the scene; when IS and Hiper Pro methods were used, only the measurements and the preliminary orientation were carried out. In case of the measuring tape me- thod, terrain measurements were followed by making a precise drawing of the scene, which was done by hand by a qualified or skilled draughtsman of the police station. When using IS and Hiper Pro tools, no additional tasks were performed.

In order to compare the accuracy of gathered data we used the ACAD software, which enabled us to compare all three sets of data at the same time. Importing the precise drawing (.img file) and adding data layers (dots and lines) acquired with IS and Hiper Pro into the ACAD environment and their spatial allocation provided us with information on the general accuracy of gathered data. Overlapping the data in the ACAD software was done with the help of spatial allocation of data acquired with the IS and Hiper Pro methods and with a scan of the precise drawing, which was aligned based on the road axis. The final result is shown in the picture (Figure 1).

The picture (Figure 1) shows that measurements done with the coordinate method do not overlap with the measurements performed with IS and Hiper Pro. The overlapping of all three measurement methods was based on the basic premise that overlapping was best done based on the road axis or from the viewpoint of adapting the driving surface. The reason for this premise is the location of the vehicles in regard to the carriageway (in order to eliminate the possibility that one driver was driving on the wrong lane).

Based on test measurements and on the precise drawing (Figure 1) we found that individual measurements performed with IS and Hiper Pro almost completely match or that there is a maximum disparity of two points in the 2D models, of up to $10 \mathrm{~cm}$ in size. In most measurements the errors are insignificant. The reason for the above mentioned disparity in measurements can also be
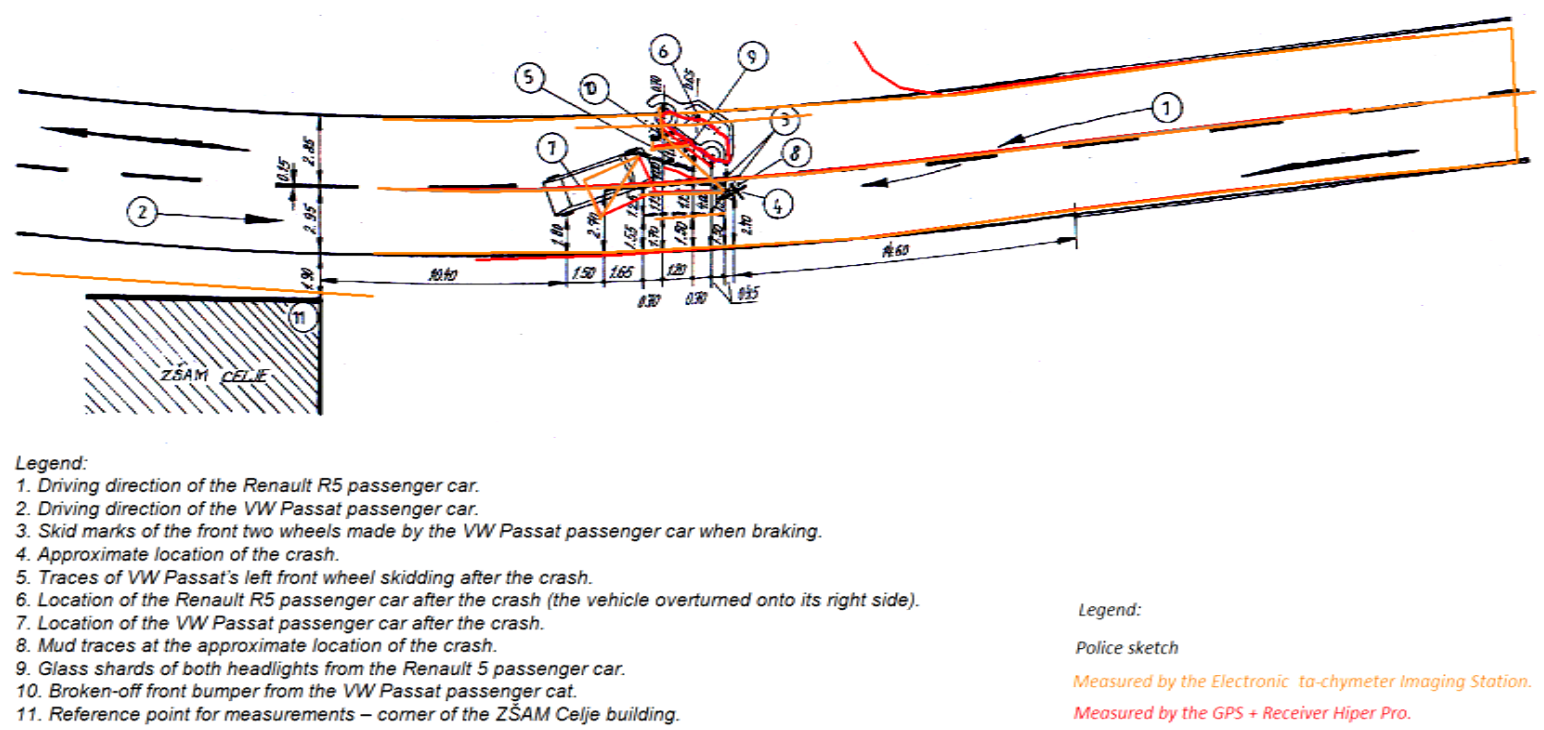

Legend:

Police sketch

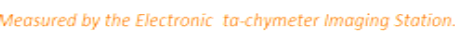

Measured by the GPS + Receiver Hiper Pro.

Figure 1. A comparison of the three measurements methods: the coordinate method, Imaging Station and GPS+ Hiper Pro receiver. 
attributed to the fact that IS and Hiper Pro measurements were done by two different persons and to the fact that the location of individual points was not pinpointed down to the exact centimetre.

However, if we compare the measurements done with IS and Hiper Pro to the ones done using the coordinate method and the precise drawing based on it, we find that there are much larger errors i.e. discrepancies between them. Based on the second picture (Figure 2) we can see that for example, the location of the VW car is not accurately placed. The rectangle shown in the picture represents the position of the vehicle's wheels and it is almost impossible to align the measurements done using the coordinate method with those done using the IS or Hiper Pro. Here, we can spot an error in IS and measuring tape measurements, in the position of individual wheels, which varies from $0.4 \mathrm{~m}$ to $1.5 \mathrm{~m}$.

Although these errors in measurement are based on single test measurements, significant discrepancies are noticeable in the measurement of individual points.

\section{Literature Overview}

An analysis of the existing literature on traffic safety and particularly on traffic accidents, measurement tools and data accuracy was based on a review of published scholarly journals, including peer-reviewed studies. Other studies were identified using IEEXplore, Proquest and ScienceDirect.

A review of the existing literature revealed a fragmentation and vagueness of research pertaining to measuring equipment for on-site data collection and underpinned the premise of the inaccuracy of certain measuring tools and methods. Our findings on the reviewed literature of the studied field are summarized below (Table 1 ).

\section{Results}

The literature review led to an analysis of existing measuring tools and methods and to defining the advantages and disadvantages of each one. Studies on the use of measuring tools and their accuracy are actually quite rare, neglected and too vaguely defined. The objective of this study was the accuracy of collected data, which significantly affects the justice of the verdict for traffic accident participants. The reviewed studies contain individual pieces of information on advantages and disadvantages of the measurement tools and the methods used in those studies; however, there is a lack of substantiation for individual statements in regard to their accuracy.

Measurements of our experimental collision scene revealed that there are mistakes or gaps in the accuracy of carried out measurements, as we had presumed there would be. The primary objective of the study was to analyse the accuracy of collected data in regard to the

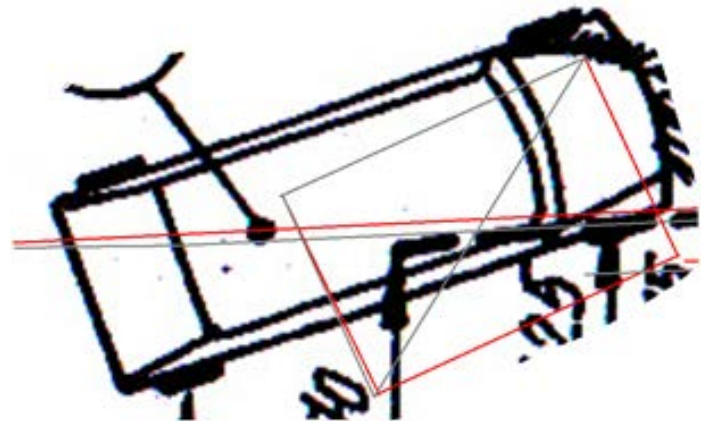

Figure 2. A detailed look at the measurement errors pertaining to VW Passat's wheel locations.

measuring tool or the method used and not to assess the remaining advantages and disadvantages of individual tools or methods. That is why the table (Table 1 ) does not contain all the advantages and disadvantages of the tested equipment, but only those that are not directly connected with additional observations like e.g. measuring the time required to collect individual pieces of data or all of them together.

The ACAD analysis of point and line data confirmed our own assumptions and the results of the studies by other authors. When performing test measurements we found it difficult to insert the precise drawing, which is based on data acquired with a measurement tape, into the ACAD environment and even more difficult to align it with the results of measurements done with IS and Hiper Pro, and to look for common points. The results of test measurements and the subsequent overlapping of individual elements therefore reveal an inaccuracy of data collected with a measuring tape and a comparable accuracy of measurements done with IS and Hiper Pro.

\section{Conclusions}

Different tools and methods for reconstruction of traffic accidents have different advantages and disadvantages. The latter can be categorized by depending on the price, portability, range, how their functionality depends on light and weather conditions, whether and to what extent the road has to be closed in order to perform measurements at the accident site or whether it is possible to carry out remote measurements, the time required to capture all data, the number of investigators required, the option of digitizing and visualising the collected data, the extent of follow-up work at the office (data processing) and particularly on the accuracy of the collected data.

The need to capture all relevant information is constrained by time pressures, and investigators typically revisit a crime scene between 8 and 12 times [11].

As a part of this study, we wanted to examine the existing tools and methods, analyse their advantages and disadvantages and test the accuracy of the data they pro- 
Table 1. A summary of studies pertaining to methodology and measuring equipment used in investigation of traffic accident scenes.

\begin{tabular}{|c|c|c|}
\hline Reference & $\begin{array}{c}\text { Methodology and Measurement } \\
\text { tools }\end{array}$ & Results and data accuracy \\
\hline
\end{tabular}

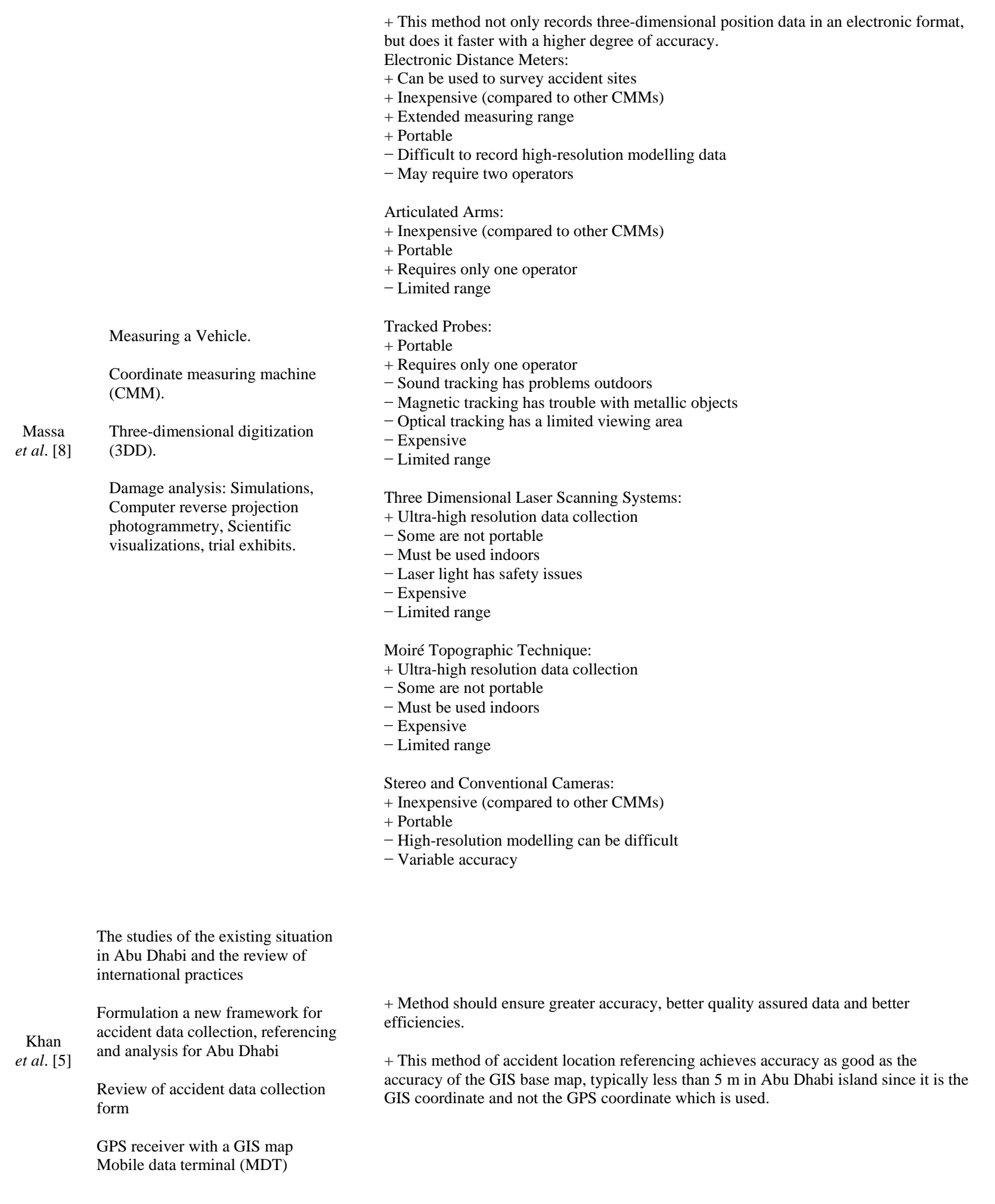




\section{Continued}

\begin{tabular}{|c|c|c|}
\hline & $\begin{array}{l}\text { Data collection at a traffic } \\
\text { accident scene. }\end{array}$ & $\begin{array}{l}\text { + Greatly reduced on-scene time. } \\
+ \text { Shorter traffic disruption periods. } \\
+ \text { Single point accuracy of } 6 \mathrm{~mm} \text { at } 50 \mathrm{~m} \text {. } \\
+ \text { A permanent } 3 \mathrm{D} \text { visual detailed record of the accident scene. }\end{array}$ \\
\hline \multirow[t]{2}{*}{$\begin{array}{l}\text { Pagounis } \\
\text { et al. [6] }\end{array}$} & $\begin{array}{l}\text { Data collection with Leica HDS2500 } \\
\text { terrestrial laser scanner. }\end{array}$ & $\begin{array}{l}\text { + Includes data collection on traffic control features, volumes, accident characteristics } \\
\text { and detailed spatial data. } \\
\text { + Terrestrial laser scanning is capable of operating reliably in daylight and darkness. }\end{array}$ \\
\hline & $\begin{array}{l}\text { The registered point clouds were used } \\
\text { to create the 3D model of the scene. }\end{array}$ & $\begin{array}{l}\text { - Wet conditions (or other unfavourable weather factors) may affect the measurements } \\
\text { on the road surfaces. } \\
\text { - Hardware related factors may affect the accuracy of collected data. }\end{array}$ \\
\hline $\begin{array}{l}\text { Forman } \\
\text { and Parry } \\
\quad[9]\end{array}$ & $\begin{array}{l}\text { Reviews use of 3D laser scanning } \\
\text { systems at major incident scenes } \\
\text { and around sensitive } \\
\text { infrastructure, briefly identifying } \\
\text { the applications and potential } \\
\text { benefits. }\end{array}$ & $\begin{array}{l}\text { + Speed and detail of remote data measurement. } \\
\text { + The high degree of scene preservation. } \\
\text { + Remote measurement of live carriageways, providing detailed road surface } \\
\text { information without closing traffic lanes. } \\
\text { + Remote measurement of live carriageways, allowing »marked-up« road traffic } \\
\text { accident scenes to be measured after the scene has been re-opened to traffic, minimizing } \\
\text { incident induced traffic delay. } \\
\text { + Presentation of raw 3D data as a method of visualizing the scene/site of interest. } \\
\text { + Visual and quantitative analysis of scene characteristics such as sightlines, open } \\
\text { ground, witness views, and the presence of visibility obstructions. } \\
\text { + Detailed data capture in daylight, or night time conditions. } \\
\text { + Generation of 3D road environment models for computerized simulated visualization } \\
\text { of crash vehicle dynamics. }\end{array}$ \\
\hline \multirow{5}{*}{$\begin{array}{l}\text { Xinguang } \\
\text { et al. [1] }\end{array}$} & $\begin{array}{l}\text { Application of photogrammetry in } \\
\text { traffic accident investigation. }\end{array}$ & \\
\hline & $\begin{array}{l}\text { Test measurement of } 16 \\
\text { reference points. }\end{array}$ & $\begin{array}{l}\text { + Photogrammetry is a time saving method. } \\
\text { + Photogrammetry is a cost effective method. } \\
\text { + Photogrammetry is suitable for analysis of various types of traffic accidents (collisions } \\
\text { between motor vehicles, collisions between non-motor vehicles and motor vehicles and }\end{array}$ \\
\hline & $\begin{array}{l}\text { The traffic policeman performed } \\
\text { traditional measurements with } \\
\text { two or three investigators using a }\end{array}$ & $\begin{array}{l}\text { collisions between motor vehicles and pedestrians etc.). } \\
+2 \mathrm{D} \text { photogrammetry method can provide sufficient accuracy in traffic accident scene } \\
\text { measurements. }\end{array}$ \\
\hline & $\begin{array}{l}\text { conventional roller tape and one } \\
\text { officer made photogrammetry }\end{array}$ & $\begin{array}{l}\text { + The results can be taken as initial input data for trajectory analysis TAR software } \\
\text { as PC-CRASH. }\end{array}$ \\
\hline & $\begin{array}{l}\text { measurements with placing the } \\
\text { evidence markers and taking the } \\
\text { required scene photographs } \\
\text { (of } 142 \text { traffic accidents). }\end{array}$ & $\begin{array}{l}\text { + The measurement accuracy by the 3D photogrammetry method can provide the initial } \\
\text { data for damage analysis TAR software such as SMAC, CRASH and PC-CRASH. }\end{array}$ \\
\hline $\begin{array}{l}\text { Fraser } \\
\text { et al. [7] }\end{array}$ & $\begin{array}{l}\text { The iWitness system (new paradigm } \\
\text { within its image measurement and } \\
\text { photogrammetric, namely automatic } \\
\text { on-line computations which are never } \\
\text { specifically invoked but occur } \\
\text { automatically in the background with } \\
\text { every image point "referencing"). }\end{array}$ & $\begin{array}{l}\text { - Laser scanning is relatively expensive and complex for local police and traffic agencies } \\
\text { - Laser scanning is mostly used in research laboratories and large centralised accident } \\
\text { investigation agencies. } \\
\text { + Laser scanning leads to more comprehensive 3D modelling. } \\
\text { - Laser scanning does not always guarantee faster data acquisition at the accident scene. } \\
\text { + iWitness enables automatic initiation of all computational functions and automatic } \\
\text { recognition of the camera(s) via information contained within the EXIF header of the } \\
\text { JPEG or TIFF images. }\end{array}$ \\
\hline $\begin{array}{l}\text { Jacobson } \\
\text { et al. }[10]\end{array}$ & $\begin{array}{l}\text { Electronic Total Station (combination } \\
\text { of an electronic distance meter, } \\
\text { which uses an infra-red light to } \\
\text { measure distance, and a theodolite, } \\
\text { or electronic transit). }\end{array}$ & $\begin{array}{l}\text { + Allows automatic distance measuring. } \\
\text { + Data from urban freeway accident investigated with total stations and the coordinate } \\
\text { method indicate an average clearance time savings of } 51 \text { minutes per investigated } \\
\text { accident ( } 50 \% \text { less time compared to classic investigation). } \\
\text { + Because the equipment can measure over the top of cars, respondents rarely have to } \\
\text { close the roadway completely, if at all. } \\
\text { + The occurrence and severity of congestion and subsequent secondary accidents, user } \\
\text { costs, excess fuel consumption, and driver frustration, are lower. } \\
\text { + Increased safety of investigators-since scene details can usually be measured from } \\
\text { one site and the total station can measure over the top of vehicles, investigators do not } \\
\text { have to stand on the roadway. } \\
\text { + Digital data-software processing at the office. } \\
\text { + Investigators require about } 2 \text { hours to finish the drawing if total stations are used for } \\
\text { measuring (classic drawing can take up to } 8 \text { hours). } \\
\text { + A more detailed accident description and more professional drawings and sketches. } \\
\text { - Equipment price. } \\
\text { - Physical restrictions-difficult use in dense fog. } \\
\text { - Measurements may be inaccurate due to high temperature (heat waves-measurement } \\
\text { can also be affected by heat waves on extremely hot days). } \\
\text { - Batteries run equipment (batteries might run down). } \\
\text { - Additional personnel training. }\end{array}$ \\
\hline
\end{tabular}




\section{Continued}

A study on the use of measuring equipment and tools at police stations.

Walton et al. [2]

Evaluation of Photogrammetry
equipment for crash site
investigation.

Measuring the axes of a triangular coordinate system method.

Current Electronic tachymeter Imaging case Station.

GPS + Receiver Hiper Pro.

Literature review.
Coordinate method:

- At least two trained investigators are required.

Total Station:

+ Make it possible to automatically measure and record distances and angles.

+ The survey data are recorded in an electronic file.

+ Generate an accurate, scale diagram of the crash scene.

+ About twice as many measurements can be taken in half the time required with the conventional coordinate method.

- This type of data collection requires a minimum of two trained officers.

Laser range finder systems:

- Expensive.

- Fragile.

- Require high maintenance.

- Not usable in all weather conditions.

- Require line of sight between the measurement points.

GPS-based system:

+ Some GPS units are accurate to within one inch or less.

+ The receiver operates on radio signals so no line of sight is required.

+ The GPS receiver requires only one person to operate.

- High cost of GPS units.

Photogrammetry:

+ Less time on scene.

+ Scenes are diagrammed only as needed.

+ Cost less than Total station.

+ Acceptable level of accuracy for accident reconstruction.

+ Training may be less than for Total station.

+ Photos can be taken by a single officer.

- More time in the office.

- Lighting may be required.

- Significant cost of equipment.

- Still in the early stages of deployment (for this application).

- Significant training is required.

- Not as effective when used on long scenes.

The coordinate method:

+ No need for special equipment.

+ Additional training of investigator/police inspectors.

- Reduced data accuracy.

- Making a croquis drawing on site and a precise drawing subsequently in the office.

- Data digitalisation is made difficult.

Electronic tachymeter Imaging Station:

+ Accuracy of the collected data.

+ 3D data (terrain diversity, road gradient)

+ The option to scan the whole area, including the capture of spatially set photographs.

+ Movement outside the accident area (remote data collection).

+ Later compatibility with other data.

+ In case of the prism measurement the work requires two people; if no prism is used, it requires only one person.

+ In case of prism measurement with the use of s Remote Control System 3 (RC-3) the work requires a single person.

+ Panoramic pictures for better understanding of the location.

- Additional training of investigator/police inspectors is required.

- Price.

GPS + Receiver Hiper Pro:

+ Data collection accuracy.

+ Later compatibility with other data.

+ Requires a single person.

+ Spatial allocation of data.

- Price.

- Satellite link required (potential problem in areas with "interference”).

Key: + represents the advantages of the measuring tool or method. - represents the disadvantages or downsides of the measuring tool or method. 
vide. Data accuracy can actually have a significant impact on the aforementioned justice of court. This of course refers to the elements, such as the precise microlocation of the event, location of traces, breaking distance, etc. which, combined with inaccurate measurements, can lead to errors in calculation of vehicle speeds prior to the crash and in errors in determining the microlocation of the crash, which is one of the primary objectives of traffic accident site reconstructions, since they serve as a basis for assessing drivers' behaviour and since the court's decision is based on whether the driver in the accident is proven guilty or not [12].

The total station with photo camera Imaging Station allows measurements with an accuracy of $\pm(2 \mathrm{~mm}+2$ ppm x D) m.s.e. when using a prism and $\pm 5 \mathrm{~mm}$ m.s.e. up to $250 \mathrm{~m}$ when not using one; for measurements up to $2000 \mathrm{~m}$, it is slightly less accurate with $\pm(10 \mathrm{~mm}+10$ ppm x D*) m.s.e. However, the reduced accuracy when working without a prism is offset by the fact that only one person is required for the task. Using the additional equipment Remote Control System 3 (RC-3) enables operation by only one person, and the measurement accuracy becomes equal to that of measurements with a prism. Compared to data acquired from literature and from reviewing the characteristics of the equipment, we can attribute similar accuracy to laser scanners, total stations, laser rangefinder systems and precise GPS systems. The GPS system Hiper Pro used in our case study features an integration of GNSS, radio, battery, Bluetooth and GNSS antenna into a single unit, which reduces the time required to finish the task. A further advantage of the Hiper Pro System is its accuracy down to a millimetre and the ability to perform point and line measurements while requiring only a single person.

Another interesting field that is related to data accuracy is photogrammetry. The accuracy of data acquired through photogrammetry depends on a number of factors like camera resolution, camera calibration method, angles between photos, photo orientation quality, photo redundancy and the use of targets. Furthermore, data processing software also affects data accuracy.

Results of the study by Randles et al. [13] show that measuring tape and photogrammetry are efficient methods for measuring vehicle points with a mean difference between the baseline and hands-on measurements of $0.6 \pm 1.4 \mathrm{~cm}$, and a mean difference between the baseline and photogrammetry measurements of $0.1 \pm 1.0 \mathrm{~cm}$. The accuracy of the photogrammetry method was found to be slightly greater than that for hands-on physical measurements.

The classic measurement method using a measuring tape, which is still the most commonly used method in the field, also has its advantages and disadvantages. Its advantages are its low price and the fact that it requires no additional equipment and no additional investigator training; however, its downsides are less accurate data, longer data collection and a more difficult subsequent data processing, which are all factors that affect the usefulness of this measuring method. But despite all that, we cannot ignore this time-proven method and the positive experience associated with it.

The tools and methods for collecting data at traffic accident scenes are well-known among the scientists and experts, and several studies have already been carried out in this field. In additions, researchers have found that other existing technologies (like GPS, which is mostly used by surveyors and in recent years for route planning in vehicles) can also be applied to this field and used for traffic accident investigation. However, we must not ignore the relationship between science and justice, which are in this case tightly intertwined, and ensure just verdicts regarding the guilt or innocence of participants in road traffic accidents.

Further studies in this field must therefore focus on additional test measurements with various tools and methods, and use of mathematical tools to ascertain the likelihood and the extent of possible mistakes.

\section{REFERENCES}

[1] X. G. Du, X. L. Jin, X. Y. Zhang, J. Shen and X. Y. Hou, "Geometry Features Measurement of Traffic Accident for Reconstruction Based on Close-Range Photogrammetry," Advances in Engineering Software, Vol. 40, No. 7, 2009, pp. 497-505.

http://dx.doi.org/10.1016/j.advengsoft.2008.09.002

[2] J. R. Walton, M. L. Barrett and K. R. Agent, "Evaluation of Methods to Limit the Time Taken to Investigate Crash Site,” Kentucky Transportation Center, Kentucky, 2005.

[3] P. Duignan, M. Griffiths and A. Lie, "Photogrammetric Methods in Crash Investigation," Proceedings of the 15th International Technical Conference on Enhanced Safety of Vehicles, Melbourne, 13-16 May 1996, pp. 1514-1518.

[4] C. S. Fraser and H. B. Hanley, "Developments in CloseRange Photogrammetry for 3D Modelling: The iWitness Example,” Processing and Visualization Using HighResolution Imagery, International Society of Photogrammetry and Remote Sensing, 2004.

[5] M. A. Khan, A. S. Kathairi and A. M. Grib, “A GIS Based Traffic Accident Data Collection, Referencing and Analysis Framework for Abu Dhabi," Proceeding Codatu XI, 2004.

[6] V. Pagounis, M. Tsakiri, S. Palaskas, B. Biza and E. Zaloumi, "3D Laser Scanning for Road Safety and Accident Reconstruction,” XXIII FIG Congress, Munich, 2006.

[7] C. S. Fraser, H. B. Hanley and S. Cronk, "Close-Range Photogrammetry for Accident Reconstruction,” Optical 3D Measurements, Vol. 7, 2005, pp. 115-127.

[8] D. Massa and B. Roger, "Using Three-Dimensional Digitization to Model a Vehicle,” Accident Reconstruction: 
Technology and Animation VIII, International Congress and Exposition, 1998.

[9] P. Forman and I. Parry, "Rapid Data Collection at Major Incident Scenes Using Three Dimensional Laser Scanning Techniques," IEEE 35th International Carnahan Conference on Security Technology, Londres, 16-19 October 2001, pp. 60-67.

[10] L. E. Jacobson, B. Legg and A. O’Brian, "Incident Management Using Total Stations,” Washington State Transportation Center, University of Washington, Washington, 1992.

[11] B. Jenkins, "Laser Scanning for Forensic Investigation”,
SparView, Vol. 3, 2005, pp. 21-22.

[12] T. Zou, Z. Yu, M. Cai and J. Liu, “Two Non-Probabilistic Methods for Uncertainty Analysis in Accident Reconstruction,” Forensic Science International, Vol. 198, No. 1, 2010, pp. 134-137. http://dx.doi.org/10.1016/j.forsciint.2010.02.006

[13] B. Randles, B. Jones, J. Welcher, T. Szabo, D. Elliott and C. MacAdams, "The Accuracy of Photogrammetry vs. Hands-On Measurement Techniques Used in Accident Reconstruction,” SAE 2010 World Congress \& Exhibition, 2010. 